\title{
The immune response to a recombinant Lactococcus lactis oral vaccine against foot-and-mouth disease virus in mice
}

\author{
Xinsheng Liu $\cdot$ Linlin Qi $\cdot$ Jianliang Lv $\cdot$ Zhongwang Zhang $\cdot$ Peng Zhou \\ Zhongyuan Ma $\cdot$ Yonglu Wang $\cdot$ Yongguang Zhang $\cdot$ Li Pan $(\mathbb{D}$
}

Received: 12 November 2019/Accepted: 24 April 2020/Published online: 9 May 2020

(C) Springer Nature B.V. 2020

\begin{abstract}
Objective Development of an effective mucosal vaccine to induce specific immune responses against Foot-and-mouth disease virus (FMDV).

Results For this purpose, the FMDV VP1 gene (SPVP1) was optimized and synthesized based on the codon bias of Lactococcus lactis (L. lactis), and then incorporated in the plasmid pNZ8148. L. lactis NZ9000 containing the pNZ8148-SPVP1 recombinant plasmid was used as an oral delivery vehicle to induce anti-FMDV mucosal and systemic immune responses in mice. After confirmation that the SPVP1 protein was expressed successfully in the recombinant L. latic, the mice were orally challenged with NZ9000pNZ8148, NZ9000-pNZ8148-SPVP1, phosphate-buffered saline as a mock infection group, or with
\end{abstract}

Xinsheng Liu and Linlin Qi have contributed equally to this study.

X. Liu · L. Qi · J. Lv · Z. Zhang $(\bowtie) \cdot$ P. Zhou •

Z. Ma $\cdot$ Y. Wang $\cdot$ Y. Zhang · L. Pan

State Key Laboratory of Veterinary Etiological Biology, National Foot-and-Mouth Disease Reference Laboratory, Lanzhou Veterinary Research Institute, Chinese Academy of Agricultural Sciences, Lanzhou, Gansu, China e-mail: zhangzhongwang@ caas.cn

Y. Zhang · L. Pan $(\bowtie)$

Jiangsu Co-innovation Center for Prevention and Control of Important Animal Infectious Diseases and Zoonoses,

Yangzhou, Jiangsu, China

e-mail: panli@caas.cn inactivated vaccine as a positive group. Mice immunized with NZ9000-pNZ8148-SPVP1 produced high levels of mucosal secretory $\operatorname{IgA}$ (sIgA), antigenspecific serum IgG, IgA, and neutralizing antibodies, and developed stronger cell-mediated immune reactions and significant $\mathrm{T}$ spleen lymphocyte proliferation. Furthermore, the recombinant group generated much higher levels of IFN- $\gamma$, IL-2, IL-4, IL-5, and IL10 than the other groups.

Conclusions Potent immune responses were successfully elicited in mice with FMDV VP1 delivered through L. lactis.

Keywords Lactococcus lactis . Oral vaccine . Mucosal immunity · Foot-and-mouth disease virus . VP1 protein

\section{Introduction}

Foot-and-mouth disease (FMD) is highly contagious and results in severe financial losses to the farming of cloven-hoofed animals. FMD virus (FMDV), grouped into the genus Aphthovirus of the family Picornaviridae, has seven different serologically distinct serotypes (O, A, C, Asia 1, SAT1, SAT2, and SAT3) with many antigenic variants of each. No cross-protective antibodies (Abs) can be detected in animals following infection or vaccination with other FMDV serotypes 
or subtypes, which has adversely affected the vaccination programs for the prevention of FMD (Jamal and Belsham 2013).

FMDV is small non-enveloped virus with an icosahedral capsid symmetry including 60 copies, and each capsomer has four structural viral proteins consisting of VP1, VP2, VP3, and VP4. Notably, the VP1 protein contains the major immunogenic epitopes including a $\mathrm{G}-\mathrm{H}$ loop and a $\mathrm{C}$-terminus which are responsible for neutralizing protective Abs (Fox et al. 1989). In addition, the cell attachment site on FMDV contains an conserved the RGD (arginine-glycineaspartic acid) motif (DiMarchi et al. 1986). Therefore, vaccination is still an effective method for the control of FMD.

Lactococcus lactis (L. lactis) is generally regarded as safe with potent effects and conveys important immunostimulant properties to both human and animals, which makes it an interesting and effective mucosal vaccination strategy. The Nisin Controlled gene Expression (NICE) system of L. lactis, developed 25 years ago, is a potent and strictly regulated protein production system depending on the auto-regulation mechanism of the bactericin nisin. Currently, this gene expression system has been widely used to express exogenous proteins in Gram-positive bacteria (Mierau and Kleerebezem 2005). Far beyond the original role in food preservation and production, L. lactis in combination with the easy-to-operate and tightly regulated NICE system has various applications, especially the expression of pathogenic antigens (Ags) for safe immunization through mucosal surfaces and production of cytokines pharmaceutical products for medical treatments. Parenteral vaccination can stimulate an effective immune response, but generally cannot effectively activate mucosal responses and fails to protect the host from pathogens invading via the mucosa. However, mucosal vaccines especially lactococci vaccines, are capable of inducing both potent mucosal immunity and systemic responses to protect against mucosal invasion. FMDV infection takes place mainly through mucosal membranes and, thus, can be blocked by mucosal immunity with vaccines designed to induce specific mucosal responses at mucosal membranes to disrupt the virion transmission (Ogra et al. 2001). Therefore, in this study, a new recombinant L. lactis strain (NZ9000) was made to express the VP1 gene from a FMDV A strain with a signal peptide sequence (SPusp45)
(Dieye et al. 2001). The aims of this research were to investigate the immunological impact of the plasmid pNZ8148 encoding FMDV-SPVP1 capsid protein through oral vaccination in a mouse model.

\section{Materials and methods}

Animal use

Female BALB/C mice, weighing 18-20 g with no maternal Abs to FMDV, were obtained from Lanzhou Veterinary Research Institute, Chinese Academy of Agricultural Sciences (LVRI, CAAS) and housed under pathogen-free conditions at $23-25{ }^{\circ} \mathrm{C}$ and relative humidity of $45-50 \%$ with free access to water and pathogen-free food. Fresh vegetables and fruits were available daily to meet the nutrient demands of the experimental animals. All the animal protocols were approved by the Institutional Animal Use and Care Committee of LVRI, CAAS guidelines on the ethical use of animals.

Bacteria, plasmids, viruses, and cell lines

All plasmids and bacterial strains applied in this research are listed in Table 1. E. coli cells were grown in Luria-Bertani (LB) broth at $37^{\circ} \mathrm{C}$ with shaking and L. lactis was cultured in GM17 medium (M17 medium with a final concentration $0.5 \%$ glucose) at $30{ }^{\circ} \mathrm{C}$ without shaking. Solid media were made by adding $1.5 \%(\mathrm{w} / \mathrm{v})$ agar to the broth. When appropriate, chloramphenicol was added at $100 \mu \mathrm{g} / \mathrm{mL}$ for E. coli and $10 \mu \mathrm{g} / \mathrm{mL}$ for L. lactis.

A DNA sequence encoding VP1 gene was obtained from FMDV/A/HB/WHHP/13 stored in our lab. A new VP1 (SPVP1), which was codon optimized with L. lactis, was synthesized by Nanjing GenScript Co. Ltd and then incorporated into pUC57 at the NcoI restriction site and contained a secretory Usp45 signal peptide (SPusp45) at the N terminus of the VP1 gene and the HindIII restriction site at the $\mathrm{C}$ terminus. The SPVP1 gene (760 bp) was digested out and then incorporated at corresponding sites of pNZ8148 (MoBiTec GmbH, Göttingen, Germany). Baby hamster kidney (BHK) cells were cultured in Dulbecco's modified Eagle's medium (DMEM; Gibco, Carlsbad, ca., USA) supplemented with $10 \%$ (v/v) fetal bovine 
Table 1 Bacterial strains and plasmids

\begin{tabular}{llc}
\hline $\begin{array}{l}\text { Plasmids or bacterial } \\
\text { strains }\end{array}$ & Relevant characteristics & $\begin{array}{c}\text { Source or } \\
\text { reference }\end{array}$ \\
\hline pUC57-SPVP1 & $\begin{array}{l}\text { Vector harboring synthetic VP1 gene with a signal peptide sequence (SPusp45) at N } \\
\text { end; Amp }\end{array}$ & This work \\
pNZ8148 & Expression vector; Cm ${ }^{\mathrm{r}}$ & MoBiTec \\
E.coli Top10 & Cloning strains of pNZ8148-SPVP1; Cm ${ }^{\mathrm{r}}$ & Takara \\
L. lactis NZ9000 & Host strain; plasmid-free & MoBiTec \\
\hline
\end{tabular}

${ }^{\mathrm{r}}$ Stands for the antibiotic resistance

serum (FBS; Gibco), $100 \mathrm{IU} / \mathrm{mL}$ of penicillin and 100 $\mu \mathrm{g} / \mathrm{mL}$ of streptomycin at $37{ }^{\circ} \mathrm{C}$ under $5 \% \mathrm{CO}_{2}$.

Electro-transformation

L. lactis were electro-transformed in accordance with the following protocol. L. lactis were cultured in G-SGM17 broth (M17 medium with $0.5 \mathrm{M}$ sucrose, $0.5 \%$ glucose and $2.5 \%$ glycerin) at $30{ }^{\circ} \mathrm{C}$ without shaking overnight and then inoculated ( $1 / 8$ inoculum) (v/v) in G-SGM17 medium until reaching an optical density at $600 \mathrm{~nm}\left(\mathrm{OD}_{600}\right)$ of 0.3 (around $3 \mathrm{~h}$ ). Afterward, the cells were washed with ice-cold buffer I (0.5 M sucrose, $10 \%$ glycerin), buffer II $[0.5 \mathrm{M}$ sucrose, $10 \%$ glycerin, $0.05 \mathrm{M}$ ethylenediaminetetraacetic acid (EDTA), $\mathrm{pH}$ 7.5], and then resuspended in buffer I. $2 \mu \mathrm{g}$ of the plasmid was added and mixed with $100 \mu \mathrm{L}$ of ice-cold competent cells, kept on ice for $3 \mathrm{~min}$, and then transferred into a prechilled cuvette (inter-electrode distance of $0.1 \mathrm{~cm}$; Bio-Rad Laboratories, Hercules, ca., USA). A single electrical pulse at $2000 \mathrm{~V} / \mathrm{cm}$ and $2.5 \mu \mathrm{F}$ was delivered via Gene Pluster $^{\mathrm{TM}}$ (Bio-Rad Laboratories). The suspension was immediately placed on ice for $5 \mathrm{~min}$ and then mixed with $890 \mu \mathrm{L}$ of LM17 broth (M17 broth without antibiotics containing $20 \mathrm{mM} \mathrm{MgCl}_{2}$ and $2 \mathrm{mM}$ $\mathrm{CaCl}_{2}$ ). Following incubation at $30{ }^{\circ} \mathrm{C}$ for $3 \mathrm{~h}$ without agitation, the recombinant strains were plated and selected on LM17 agar medium containing $10 \mu \mathrm{g} / \mathrm{mL}$ of chloramphenicol.

\section{Protein expression detection}

To analyze the SPVP1 expression in NZ9000, the recombinant strains were cultured in GM17 broth supplemented with $10 \mu \mathrm{g} / \mathrm{mL}$ of chloramphenicol at $30{ }^{\circ} \mathrm{C}$ for $12 \mathrm{~h}$ without shaking. The overnight cultures were inoculated (1/50 inoculum) (v/v) in GM17 broth and induced by adding $10 \mathrm{ng} / \mathrm{mL}$ of nisin at $\mathrm{OD}_{600} 0.3$ (around $3 \mathrm{~h}$ ). Bacterial cells were harvested at $\mathrm{OD}_{600}$ 1.0 by centrifugation at $6000 \mathrm{rpm}$ at $4{ }^{\circ} \mathrm{C}$ and then washed three times with sterile, ice-cold phosphatebuffered saline (PBS, pH 7.4) at $4{ }^{\circ} \mathrm{C}$. The pelleted cells were resuspended in PBS and recombinant proteins were prepared after ultrasonic decomposition for analysis through $15 \%$ sodium dodecyl sulphatepolyacrylamide gel electrophoresis (SDS-PAGE). Protein extracts were electro-transferred onto a PVDF membrane for western blot analysis using guinea pig anti-FMDV Abs (dilution, 1:1000; prepared in our lab) at 1:1000 dilution and horseradish-peroxidase (HRP)conjugated goat anti-guinea pigs IgG Ab (dilution, 1:2000; Abbkine Scientific Co., Ltd., Wuhan, Hubei, China) and then visualized with chemiluminescent substrate reagent using Gel $\operatorname{Doc}^{\mathrm{TM}} \mathrm{XR}+$ system (BioRad).

\section{Immunization procedures}

Bacterial cells (NZ9000-pNZ8148-SPVP1 and NZ9000-pNZ8148) cultured in GM17 broth supplemented with $10 \mu \mathrm{g} / \mathrm{mL}$ of chloramphenicol, induced at $\mathrm{OD}_{600} 0.4-0.6$ with nisin at a final concentration of 10 $\mathrm{ng} / \mathrm{mL}$ at $30{ }^{\circ} \mathrm{C}$ and collected at $\mathrm{OD}_{600} 1.0$, were washed with PBS. The mice were randomly divided into four groups ( $\mathrm{n}=25 \mathrm{each}$ ) as described in Table 2 . Infection-free mice in the NZ9000(pNZ8148-SPVP1) and NZ9000(pNZ8148) groups were orally dosed with the L. lactis strains every 7 days with $100 \mu \mathrm{L}$ of $10^{9}$ colony forming units (CFU) in $100 \mu \mathrm{L}$ of PBS for three consecutive days (i.e., days 1-3, 11-13, and 21-23), using inactivated FMDV vaccine as a positive control (intramuscular injection once on day 1) and PBS as a 
Table 2 Immunization schedule

\begin{tabular}{lllll}
\hline Groups & Number & Immunizing dose & Vaccines & Immunizing methods \\
\hline A & 25 & $0.1 \mathrm{~mL}\left(10^{9} \mathrm{CFU} / \mathrm{mL}\right)$ & NZ9000(pNZ8148-SPVP1) + PBS & Oral vaccination \\
B & 25 & $0.1 \mathrm{~mL}\left(10^{9} \mathrm{CFU} / \mathrm{mL}\right)$ & NZ9000(pNZ8148) + PBS & Oral vaccination \\
C & 25 & $0.1 \mathrm{~mL}\left(10^{9} \mathrm{CFU} / \mathrm{mL}\right)$ & Inactivated FMDV vaccine & Intramuscular injection \\
D & 25 & $0.1 \mathrm{~mL}(100 \mu \mathrm{g} / \mathrm{mL})$ & PBS & Oral vaccination \\
\hline
\end{tabular}

CFU colony forming unit

blank group (same immunization schedule as the experimental groups).

Preparation of blood, serum, intestinal mucus, and lung fluid samples

The mice were anaesthetized with ether before sacrifice. On days $0,10,20,30,37,44$, and 51, 100 $\mu \mathrm{L}$ of anticoagulated whole blood and $200 \mu \mathrm{L}$ of blood for serum testing were collected by orbital puncture. Intestinal mucus samples in $300 \mu \mathrm{L}$ of sterile PBS and lung liquid samples in $200 \mu \mathrm{L}$ of sterile PBS (3 mice in each group per time) were collected by cotton swabs into tubes containing $0.01 \mathrm{M} / \mathrm{L}$ EDTA- $\mathrm{Na}_{2}$, and rinsed repeatedly.

\section{Detection of Abs}

Specific immunoglobulin (Ig) $\mathrm{G}$ in serum was tested using an indirect enzyme-linked immunosorbent assay (ELISA) and a capture ELISA was used to detect the level of IgA and $\operatorname{sIgA}$, as described previously (Wang et al. 2015). For the indirect ELISA for detection of $\mathrm{IgG}$, the wells of a 96-well microplate (Costar; Corning Incorporated, Corning, NY, USA) were coated with FMDV-A Ag (prepared in our lab previously) overnight at $4{ }^{\circ} \mathrm{C}$ and the working concentration of FMDV-A Ag is $1 \mu \mathrm{g} / \mathrm{mL}$ in $0.05 \mathrm{M}$ bicarbonate buffer. After washing five times with PBS + Tween $20(0.1 \%)($ PBST), the wells were blocked at $37{ }^{\circ} \mathrm{C}$ with PBST containing 5\% skim milk for $2 \mathrm{~h}$ and then washed five times with PBST. Afterward, serum (from 1:4 dilution) with a double ratio dilution method was reacted with the coated wells for $1 \mathrm{~h}$ at $37^{\circ} \mathrm{C}$. After washing five times, HRPconjugated goat anti-mouse $\operatorname{IgG~Ab}$ (dilution, 1:2,000) was added to the plates for an additional hour at $37^{\circ} \mathrm{C}$.
After washing five times, o-phenylenediamine (OPD) was added for color development, and 15 min later, the enzymatic reaction was blocked by the addition of stop buffer. Then, the optical absorbance of each well was tested on a spectrophotometer at $492 \mathrm{~nm}$.

A capture ELISA was used to detect IgA in serum and $\operatorname{sIgA}$ in intestinal and lung fluids. The wells of 96-well plates were coated at $22{ }^{\circ} \mathrm{C}$ with rabbit antiFMDV serum (dilution, 1:1,000) overnight and washed five times with PBST. Then the plates were incubated with FMDV-A Ag (1:6 dilution) at $37^{\circ} \mathrm{C}$ for $1 \mathrm{~h}$, followed by five washes with PBST. The test samples were added with a double ratio dilution method (serum from 1:10 dilution, intestinal mucus from 1:2 dilution, and lung fluid from 1:1 dilution) and incubated at $37^{\circ} \mathrm{C}$ for $1 \mathrm{~h}$. Following five washes, the samples were incubated with HRP-conjugated goat anti-mouse IgA Ab (dilution, 1:2,000) for an additional hour at $37{ }^{\circ} \mathrm{C}$ to detect bound Abs. After washing five times, color development was conducted with OPD as the substrate for $15 \mathrm{~min}$. After the addition of the stop buffer, optical absorbance was measured with a spectrophotometer at $492 \mathrm{~nm}$.

\section{Detection of neutralizing Abs}

Serum samples (inactivated at $56{ }^{\circ} \mathrm{C}$ for $30 \mathrm{~min}$ ) collected on days 10, 20,30, 37, 44 and 51 were analyzed for neutralizing Ab titers with BHK-21 cells. Briefly, 50- $\mu \mathrm{L}$ aliquots of sera samples from each group were added to the wells of a 96-well plate by the double ratio dilution. Free anti-FMDV serum was used as a negative control (dilution from 1:2 to 1:4), antiFMDV serum as a positive control (both serum were prepared previously in our lab), and DMEM with $2 \%$ FBS as a blank control. Then, $50 \mu \mathrm{L}$ of FMDV, adjusted to 200 median tissue culture infectious dose $\left(\mathrm{TCID}_{50}\right) / 100 \mu \mathrm{L}$, were added to the plates containing 
serially diluted serum. The mixtures were incubated at $37^{\circ} \mathrm{C}$ for $1 \mathrm{~h}$, and then $100 \mu \mathrm{L}$ of BHK cells $\left(10^{6}\right.$ cells/ $\mathrm{mL}$ ) were plated to the wells followed by incubation at $37^{\circ} \mathrm{C}$ for 5 days under $5 \% \mathrm{CO}_{2}$. Finally, the cytopathic effect (CPE) of each serum dilution was measured by microscopy. The supernatant was removed followed by addition of $50 \mu \mathrm{L}$ of stationary liquid $(10 \%$ formaldehyde). After incubation for $30 \mathrm{~min}$, the plates were stained with $10 \%$ formaldehyde containing $0.05 \%$ methylene blue solution for $30 \mathrm{~min}$. The neutralizing Ab titers were calculated in this study, based on the Reed and Muench method, as the $\log _{10}$ of the reciprocal of the final serum dilution that neutralized 100 TCID $_{50}$ of virus in $50 \%$ of the wells.

Carboxyfluorescein diacetate succinimidyl ester (CFSE) proliferation assay

Three mice from each group were dissected under aseptic conditions and lymphocyte suspensions were prepared from the spleen on day 30. Lymphocytes were labeled with CFSE. After washing three times with PBS containing 3\% FBS, CFSE-labeled cells were resuspended in RPMI containing $10 \%$ FBS, 15 $\mathrm{mM}$ HEPES, and $0.05 \mathrm{mM} ß$-mercaptoethanol. Then, single cell suspensions at $2.0 \times 10^{6}$ cells $/ \mathrm{mL}$ were added to each well of a 24 -well plate. The cells were split into three groups: the first group was stimulated with $10 \mu \mathrm{g} / \mathrm{mL}$ of inactivated FMDV Ags (specific Ag stimulation), the second group was stimulated with 10 $\mu \mathrm{g} / \mathrm{mL}$ of concanavalin A (con A) as a positive control, and the third with culture medium as a negative control. Three parallel repetitions for each group were incubated at $37{ }^{\circ} \mathrm{C}$ for 3 days under $5 \%$ $\mathrm{CO}_{2}$. Afterward, the lymphocytes were collected and washed three times with PBS and then resuspended in $300 \mu \mathrm{L}$ of PBS. Subsequently, T cell proliferation was measured using a FACSAria flow cytometer (BD Immunocytometry Systems, San Jose, ca., USA).

Determination of T lymphocyte subsets

Mice blood samples collected on day 30 into tubes containing the anticoagulation agent EDTA were stained with RPE-conjugated rat anti-mouse CD4 $\mathrm{Ab}$ and FITC-conjugated rat anti-mouse $\mathrm{CD} 8 \mathrm{Ab}$ at $37^{\circ} \mathrm{C}$ for $30 \mathrm{~min}$ in the dark. The blood samples stained with RPE-conjugated rat IgG2a and FITC-conjugated rat IgG2b Abs are negative controls. FACS lysing solution (BD FACS ${ }^{\mathrm{TM}}$ ) was added to lyse the blood cells at $37^{\circ} \mathrm{C}$ for $15 \mathrm{~min}$. After three washes with PBS, the $\mathrm{T}$ lymphocyte subsets were detected using a FACSAria flow cytometer.

\section{Determination of cytokines in serum}

The cytokine concentrations of mouse serum samples collected on days 37 and 51 were determined. The concentrations of 20 cytokines were quantified using the Quantibody Mouse Cytokine Array 1 (RayBiotech, Inc., Norcross, GA, USA) according to the manufacturer's instructions, which included interferon (IFN)- $\gamma$, interleukin (IL)-1a, IL-1b, IL-2, IL-3, IL-4, IL-5, IL-6, IL-9, IL-10, IL-12p70, IL-13, IL-17, keratinocyte chemoattractant (KC), monocyte chemoattractant protein 1, macrophage colony-stimulating factor, RANTES (Regulated upon Activation, Normal $\mathrm{T}$ cell Expressed, and Secreted), tumor necrosis factor- $\alpha$, and vascular endothelial growth factor.

\section{Statistical analysis}

Data analysis and graphic representation were performed using GraphPad Prism 6.0 software (GraphPad Software, Inc., La Jolla, ca., USA). The results are expressed as the mean \pm standard deviation (SD). The one-tailed $t$ test was used for comparison. A probability $(p)$ value of $<0.05$ was considered statistically significant.

\section{Results}

\section{Expression of SPVP1 by L. lactis NZ9000}

The strain cultures were harvested and subjected to SDS-PAGE followed by immunoblotting. As expected, the recombinant protein SPVP1 $(\sim 27$ $\mathrm{kDa}$ ) was expressed in L. lactis NZ9000 containing the recombinant plasmid after induction with nisin (Fig. 1), whereas no bands were evident in the nonnisin induced NZ9000 strains or in the nisin-induced NZ9000 strain carrying the plasmid pNZ8148 (negative control lanes). 

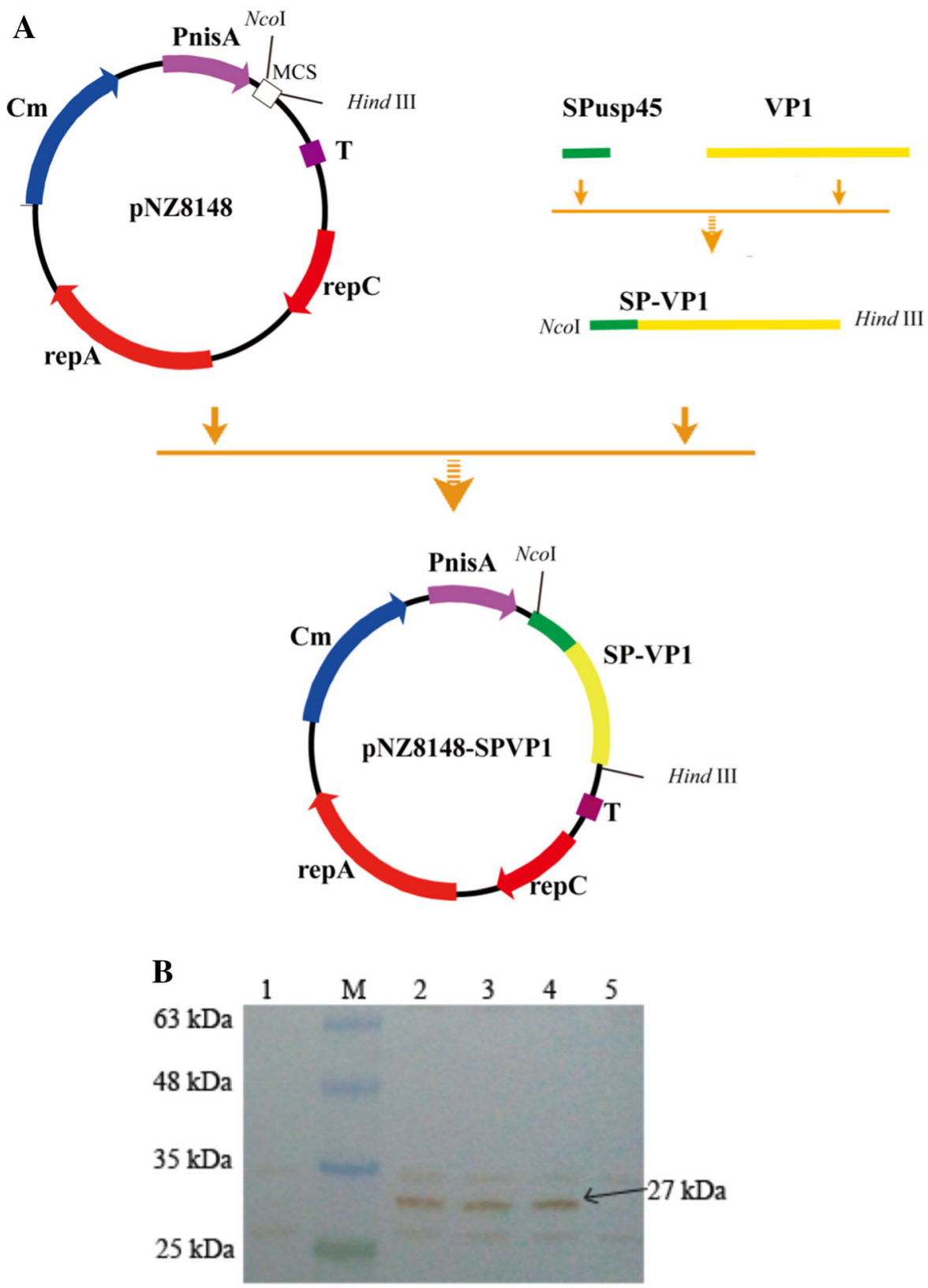

Fig. 1 Recombinant plasmid structure of pNZ8148-SPVP1 and the detection of SPVP1 protein expressed by N9000 by western blot analysis. a The pNZ8148-SPVP1 plasmid was made as described in the article. The yellow arrow indicates optimized VP1 and the green arrow indicated the signal peptide. b The SPVP1 proteins expressed in NZ9000 were detected by western blot analysis. Lane 1: NZ9000/ pNZ8148-SPVP1 without an

\section{$\mathrm{Ab}$ responses}

The mucosal immune responses were investigated by testing the level of anti-FMDV-SPVP1 $\operatorname{IgA}$ in serum. inducer; M: Protein marker; Lane 2: NZ9000/ pNZ8148-SPVP1 with nisin for $2 \mathrm{~h}$; Lane 3: NZ9000/ pNZ8148-SPVP1 with nisin for $3 \mathrm{~h}$; Lane 4: NZ9000/ pNZ8148-SPVP1 with nisin for $4 \mathrm{~h}$; Lane 5: NZ9000/ pNZ8148 with nisin as a control. Pnis nisininducible promotor; repA and repC replication elements; $T$ transcriptional terminator; $\mathrm{Cm}$ chloramphenicol-resistance marker; $M C S$ multiple cloning site

Before oral immunization, there was no difference in mucosal IgA levels among the four groups $(p>0.05)$ (Fig. 2). During the three immunizations (from day 0 to day 30), IgA Ab in the NZ9000/pNZ8148-SPVP1 


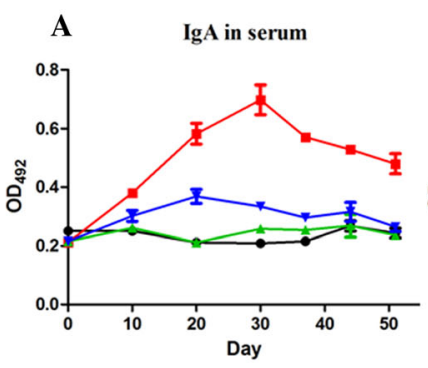

D

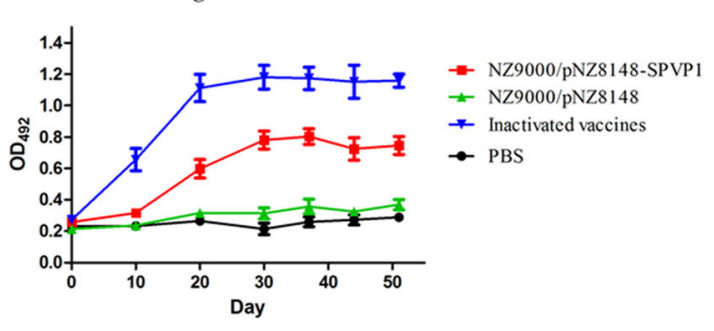

Fig. 2 Levels of SPVP1-specific Abs and neutralizing Ab titers between the experimental and control groups. a $\operatorname{IgA~Ab}$ in serum was mesaured by capture ELISA on days 0, 10, 20, 30, 37, 44, and 51. $\mathbf{b} \operatorname{SIgA~Ab}$ in the intestinal tract was mesaured by capture ELISA on days $0,10,20,30,37,44$, and 51. c sIgA Ab in lungs was mesaured by capture ELISA on days $0,10,20,30,37,44$, and 51. d IgG Ab in serum was detected by indirect ELISA on

group increased continuously and reached the highest level on day 30 , but decreased gradually afterwards, while there was no obvious increase in $\operatorname{Ig} \mathrm{A} \mathrm{Ab}$ among the other three groups, with the exception of a minimal increase in the inactivated vaccine group on day 20 $(p>0.05)$. Similar results for sIgA Ab were observed for intestinal fluid samples in the immunized mice (Fig. 2a, b). In lung fluid, the level of sIgA $A b$ in the NZ9000/pNZ8148-SPVP1 group increased slightly on day 30 . The systemic immune responses of mice were investigated by testing IgG levels in serum. As shown in Fig. 2d, there was no dramatic difference in the level of IgG among the four groups on day $0(p>0.05)$. On day 10 (7 days after the first immunization), IgG levels were high in the inactivated vaccine group $(p<0.05)$ and reached the highest level on day 30 , which was maintained afterward $(p<0.05)$. As in the recombinant strain group, IgG also gradually increased from day 0 to day 30 and maintained a high concentration until day 50, but remained lower than $\operatorname{IgG}$ in the inactivated vaccine group. No significant elicitation of IgG Abs was observed in the PBS and NZ9000/ pNZ8148 groups $(p>0.05)$. These data indicate that oral administration of NZ9000/pNZ8148-SPVP1 was

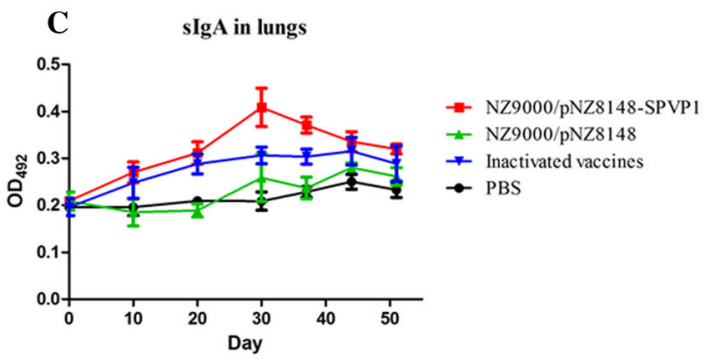

E

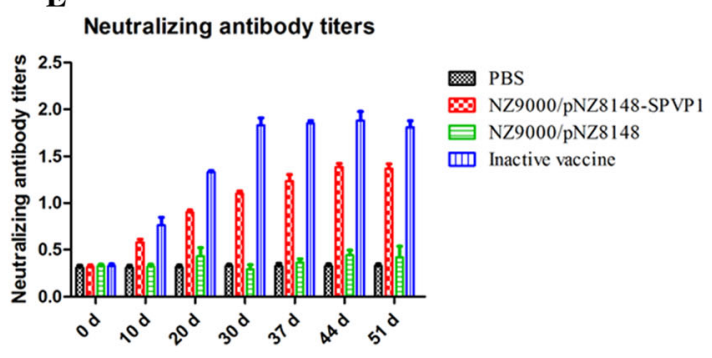

days $0,10,20,30,37,44$, and 51. e Titers of neutralizing Abs. The neutralizing Ab titers in serum were determined against 200 $\mathrm{TCID}_{50}$ per $0.1 \mathrm{ml}$. Data are expressed as the mean of optical density $(\mathrm{OD}) \pm \mathrm{SD}(\mathrm{n}=03) .{ }^{*} p<0.05$ vs. the PBS control group; $* * p<0.01$ vs. the PBS control group. Ig immunoglobulin; $S D$ standard deviations

capable of eliciting both mucosal and systemic $\mathrm{Ab}$ responses. Furthermore, the mucosal immune responses induced by the recombinant L. lactis were stronger than the responses induced by the inactivated vaccine.

Determination of $\mathrm{T}$ lymphocyte subsets

To examine cellular immune responses following immunization, $\mathrm{CD}^{+}$and $\mathrm{CD}^{+} \mathrm{T}$ cells in blood samples obtained on day 30 were assayed by flow cytometry. As shown in Fig. 3, the $\mathrm{CD} 4^{+} \mathrm{T}$ cells in the NZ9000/pNZ8148-SPVP1, NZ9000/pNZ8148, and inactivated vaccine groups rose to high levels with the former group reaching the highest level. While $\mathrm{CD}^{+}$cells in the recombinant strain group rose slightly, there was no obvious increase in the other three groups. Above all, the cellular responses of $L$. lactis NZ9000 were the same as the inactivated vaccines. Furthermore, the recombinant strains induced both cellular and humoral immune responses, with the former type being predominant. 

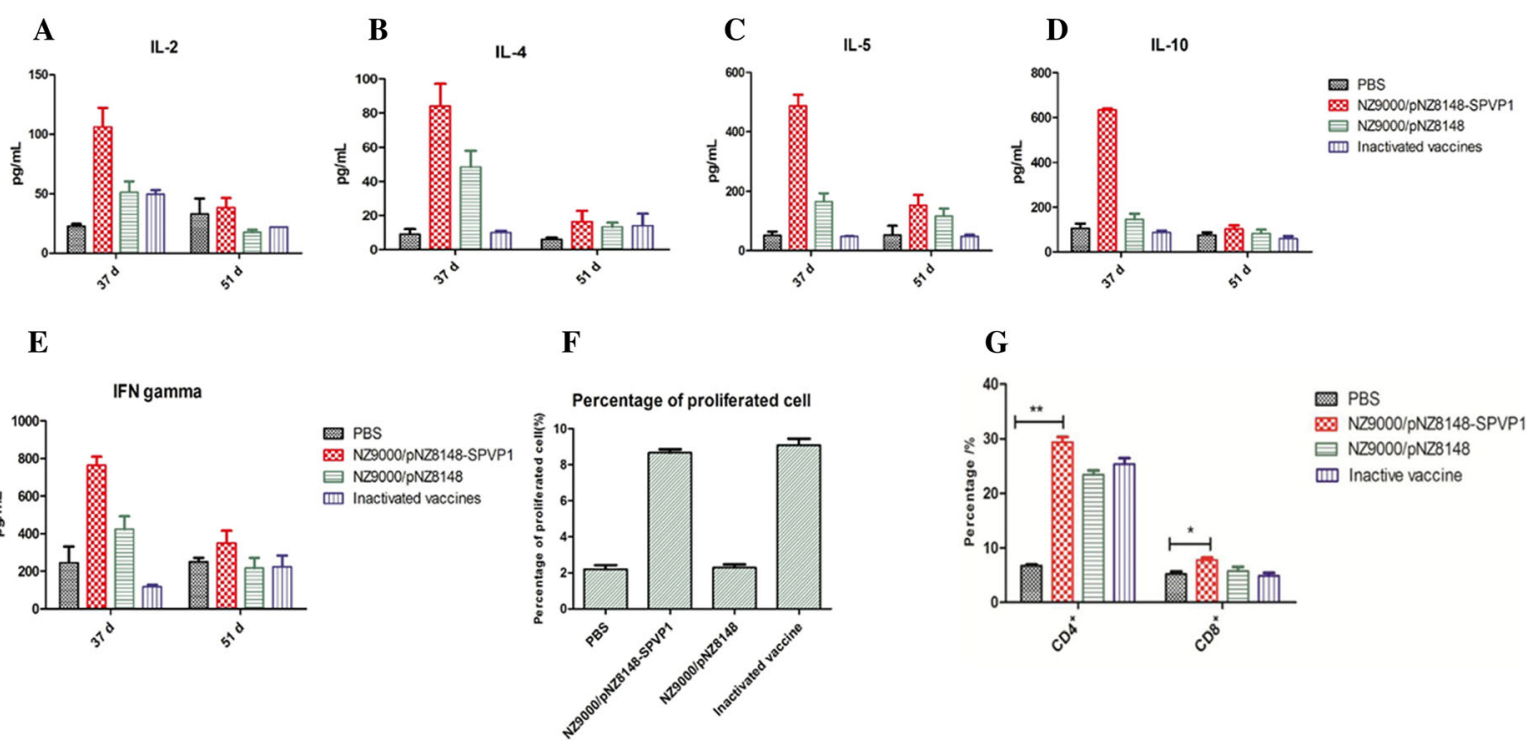

Fig. 3 Serum levels of cytokines, detection of CD4 ${ }^{+}$and $\mathrm{CD} 8^{+}$ $\mathrm{T}$ cells, and T-lymphocyte proliferation. Expression levels of a IL-2, b IL-4, c IL-5, d IL-10, e and IFN- $\gamma$. f The percentages of

$\mathrm{T}$ cell proliferative responses

The lymphocyte suspensions were stimulated with con A as a positive control, which showed evident proliferation, and by medium as a negative control, with evident dormancy as expected. T cell proliferation was notably increased in both the recombinant $L$. lactis and inactivated vaccine groups when stimulated by specific FMDV Ag in Fig. 3f, while no significant proliferation shown in the control groups. Taken together, these results suggest that the L. lactis expressing FMDV VP1 protein could induce Agspecific $\mathrm{T}$ cell immune responses.

\section{$\mathrm{Ab}$ titers in mice serum}

The neutralizing Ab titers of immunized mice on day 30 were assessed. As shown in Fig. 2e, the antibody responses of mice immunized with bothNZ9000pNZ8148-SPVP1 and inactivated vaccines showed higher FMDV-neutralizing activity than that of the control group, evaluated by CPE inhibition, suggesting that the recombinant $L$. lactis is able to induce neutralizing Abs to FMDV.
T-lymphocyte proliferation on day 30 . $\mathbf{g}$ The percentages of $\mathrm{CD}^{+}$and $\mathrm{CD}^{+} \mathrm{T}$ cell on day 30. IL interleukin; $P B S$ phosphate buffer solution

Expression of cytokines in mice

IL-2, IL-4, IL-10 and IL-12 can affect FMDV replication by activating dendritic cells and recruiting NK cell (Natural killer cell dysfunction during acute infection with footand-mouth disease virus). IFN- $\gamma$ may affect persistent infection of FMDV, and IL-1, IL-6, IL-10, TNF- $\alpha$ and RANTES are responsible for the control of viral replication and transmission (Dash et al. 2010; Segundo et al. 2012). Of the 20 cytokines in serum, five (IFN- $\gamma$, IL-2, IL-4, IL-5, and IL-10) were increased in the NZ9000-pNZ8148-SPVP1 and NZ9000-pNZ8148 groups on day 37, as compared with the PBS control group. Furthermore, the expression levels of these five cytokines were significantly increased in the recombinant strain group, as compared with the other groups. However, the expression levels of all five cytokines returned to normal with no differences among the four groups on day 51 .

\section{Discussion}

Since the early 1990s, FMD has been the primary sanitary barrier to the profitability of livestock products. Although many types of vaccines have been designed and applied to prevent FMDV infection, 
there have been some disadvantages, such as insufficient stability and reversion to virulence. It is worth mentioning that many commercial inactivated vaccines are able to induce high levels of neutralizing Abs providing protection against homologous serotypes, but yet fail to prevent the virus from infecting the host via the mucosa. Meanwhile, vaccines designed on basis of mucosal immunity have been shown to successfully trigger mucosal immune responses to prevent viruses from establishing mucosal sites to continue replication and dissemination (Yigang and Yijing 2008), and more importantly, they can also elicit systemic IgG Abs as well as Ag-specific mucosal sIgA Abs. Consequently, the use of mucosal vaccines could be a much more promising approach applied in a similar way as current licensed parenteral vaccines (Fujkuyama et al. 2012). FMDV generally infects animals via mucosal surfaces, which offers an attractive option for mucosal immunization with specific vaccine Ags for protection against infection. Sufficient data are now available to support the use of mucosal immunization to induce both mucosal and systemic responses to protect animals against FMDV. A previous study indicated that intranasal delivery of cationic poly (lactic-co-glycolic acid) (PLGA) nanoparticles loaded with different FMDV DNA vaccine formulations encoding IL-6-enhanced protective immunity prevented infection from aerosolized FMDV (Wang et al. 2011). Another publication showed that intranasal delivery of Chi-PLGA-DNA nanoparticles with FMDV Ags also decreased disease severity and virus excretion as well as delayed the onset of clinical symptoms with high levels of systemic, mucosal and cell-mediated immunity (Pan et al. 2014).

Many available approaches using L. lactis to deliver exogenous vaccines Ags have been shown to efficiently stimulate mucosal responses. Oral administration of lactococci expressing viral antigens in situ has a number of advantages, including safety, convenience, fewer proteases, and no endotoxin prompting adverse reactions (Bermudez-Humaran 2009; Bermudez-Humaran et al. 2011). Besides, L. lactis has been used to deliver many recombinant Ags, which can provoke the host mucosal and systemic responses with better protection. Some food-grade live vaccines have been developed and found to convey protective effects to animals under laboratory conditions, thereby providing a new direction for oral vaccines (expression of severe acute respiratory syndromerelated coronavirus nucleocapsid protein, production, and targeting of the Brucella abortus Ag, while a mucosal vaccine made from live, recombinant $L$. lactis protected mice). However, although lactococci have many potential advantages as carriers of live vaccines, no study has yet to investigate oral immunization with L. lactis for prevention against FMDV. Over the last several decades, the VP1 coding sequence has been partially or completely applied in vaccine design for the large-scale preparation of recombinant proteins in different expression systems, including $E$. coli, yeasts, baculovirus, plants, and mammalian cells (Chai et al. 2013; Jung et al. 2013; Lentz et al. 2010; Li et al. 2008; Parida et al. 2006; Shi et al. 2006) and thus FMDV VP1 was chosen for mucosal vaccine design in this study. The VP1 protein is the primary Ag inducing neutralizing $\mathrm{Ab}$ responses and plays a vital role in the assembly of FMDV particles (Yin et al. 2014). Here, the sequence of VP1 was optimized according to the pool and codon used by L. lactis, by decreasing the GC content from 55.29-35.18\%, without altering the protein sequence and optimizing unfavorable GC peaks, which could improve translational performance (Jiang et al. 2014). The signal peptide SPusp45, located at the $\mathrm{N}$ terminus of the VP1 gene, is a secreted extracellular protein of L. Lactis, and is usually used to direct extracellular secretion of any protein of interest. In addition, the NICE system was applied to express the FMDV-SPVP1 protein and strain NZ9000 was chosen to carry the pNZ8148 plasmid. Expression of the VP1 sequence by pNZ8148 without the signal peptide SPusp45 failed, while the fusion protein was only successfully expressed by fusing SPusp45 downstream of the VP1 sequence. Due to this signal peptide, both intracellular and extracellular expression of VP1 can be detected with immunoreactive bands.

Under normal conditions, production of the $\operatorname{Ig} \mathrm{A} \mathrm{Ab}$ is earlier than that of the $\mathrm{IgG} \mathrm{Ab}$ following infection via the mucosa, reflecting that $\operatorname{IgA}$ performs an important function at the early stage of infection. Likewise, mucosal vaccines can induce $\operatorname{sg} \mathrm{A}$ and $\operatorname{IgA}$ Abs in the adaptive immune defense of mucosa. The results of the present study also showed that high levels of specific $\operatorname{IgA}$ and $\operatorname{sIgA}$ were observed in serum, lungs, and intestinal tract, indicating the important roles of $\operatorname{IgA}$ and $\operatorname{sIgA}$ responses in preventing FMDV. Although, IgG Ab emerges later that IgA and $\operatorname{sIg} \mathrm{A}$, the levels were much higher and lasted 
longer. These data suggested that mucosal responses induced by recombinant $L$. lactis were interactive with systemic responses. Although the inactivated vaccine group had the highest serum levels of IgG Ab, there was a very slight or no increase of $\operatorname{IgA}$ and $\operatorname{sg} \mathrm{A}$ in the mucosal samples, as high IgG concentrations occurred on day 20 after the first vaccination.

The present study is the first to report the effects of oral immunization of mice using the NICE system with L. lactis strain NZ9000. The results obviously showed that oral administration of SPVP1 proteins is able to trigger both mucosal and systemic responses. Although this mucosal VP1 protein-based vaccine contributed to a detectable FMDV-specific IgG and IgA responses, as a result of VP1 gene frequent mutations, it was not possible to produce a both stable and effective immune response of the host. At present, many groups are exploring alternative genes containing effective immuno-dominant epitopes with fewer mutations. For instance, VP2 is thought to carry immuno-dominant epitopes and has essential immunological characteristics for the design of FMDV vaccines (Xue et al. 2012). Ongoing studies by our group are also exploring the immune effects of other FMDV gene segments, such as P12A3C in combination IFN- $\gamma$ expressed by lactic acid bacteria via mucosal routes in mice, guinea pigs, and swine. However, those studies are still in preliminary stages, thus further data are needed from different animal models, especially large animals, and different immunization routes are required to compare and optimize immunization programs, such as comparisons with the intranasal and oral immunizations, the co-expression of larger fragments and cytokines, the optimal dose of therapeutic protein delivered in situ, and the best period of life for vaccination.

In this study, a live L. lactis vaccine expressing VP1 was constructed, which was effective as an oral vaccine in $\mathrm{BALB} / \mathrm{C}$ mice. The recombinant strain vaccine induced both humoral and cellular responses and improved the immune system in comparison with the control groups. However, further studies are needed to explore the mechanism of this vaccine to protect against FMDV and there is still a long way to study its various effects on different experimental animals, optimal immunization route, and co-operation with other fragments and cytokines.
Acknowledgements This study was funded by the National Key Research and Development Program of China (Grant Nos. 2017YFD0501104 and 2016YFD0501503), the National Natural Science Foundation of China (Grant No. 31772780), and the China Agriculture Research System (Grant No. CARS$35)$.

\section{References}

Bermudez-Humaran LG (2009) Lactococcus lactis as a live vector for mucosal delivery of therapeutic proteins. Hum Vaccines 5(4):264-267. https://doi.org/10.4161/hv.5.4. 7553

Bermudez-Humaran LG, Kharrat P, Chatel JM, Langella P (2011) Lactococci and lactobacilli as mucosal delivery vectors for therapeutic proteins and DNA vaccines. Microb Cell Fact. https://doi.org/10.1186/1475-2859-10-S1-S4

Chai Z, Wang H, Zhou G, Yang D, Wang J, Yu L (2013) Adenovirus-vectored type Asial foot-and-mouth disease virus (FMDV) capsid proteins as a vehicle to display a conserved, neutralising epitope of type O FMDV. J Virol Methods 188(1-2):175-182. https://doi.org/10.1016/j. jviromet.2012.08.021

Dash P, Barnett PV, Denyer MS, Jackson T, Stirling CM, Hawes PC, Simpson JL, Monaghan P, Takamatsu HH (2010) Footand-mouth disease virus replicates only transiently in welldifferentiated porcine nasal epithelial cells. J Virol 84(18):9149-9160. https://doi.org/10.1128/JVI.00642-10

Dieye Y, Usai S, Clier F, Gruss A, Piard JC (2001) Design of a protein-targeting system for lactic acid bacteria. J Bacteriol 183(14):4157-4166. https://doi.org/10.1128/JB.183.14. 4157-4166.2001

DiMarchi R, Brooke G, Gale C, Cracknell V, Doel T, Mowat N (1986) Protection of cattle against foot-and-mouth disease by a synthetic peptide. Science 232(4750):639-641

Fox G, Parry NR, Barnett PV, McGinn B, Rowlands DJ, Brown F (1989) The cell attachment site on foot-and-mouth disease virus includes the amino acid sequence RGD (arginine-glycine-aspartic acid). J Gen Virol 70(Pt 3):625-637. https://doi.org/10.1099/0022-1317-70-3-625

Fujkuyama Y, Tokuhara D, Kataoka K, Gilbert RS, McGhee JR, Yuki Y, Kiyono H, Fujihashi K (2012) Novel vaccine development strategies for inducing mucosal immunity. Expert Rev Vaccines 11(3):367-379. https://doi.org/10. 1586/erv.11.196

Jamal SM, Belsham GJ (2013) Foot-and-mouth disease: past, present and future. Veterinary research 44:116. https://doi. org/10.1186/1297-9716-44-116

Jiang X, Yu M, Qiao X, Liu M, Tang L, Jiang Y, Cui W, Li Y (2014) Up-regulation of MDP and tuftsin gene expression in Th1 and Th17 cells as an adjuvant for an oral Lactobacillus casei vaccine against anti-transmissible gastroenteritis virus. Appl Microbiol Biotechnol 98(19):8301-8312. https://doi.org/10.1007/s00253-0145893-2

Jung JG, Lee YJ, Velmurugan N, Ko YJ, Lee HS, Jeong KJ (2013) High-yield production of the VP1 structural protein epitope from serotype $\mathrm{O}$ foot-and-mouth disease virus in Escherichia coli. J Ind Microbiol Biotechnol 
40(7):705-713. https://doi.org/10.1007/s10295-013-12737

Lentz EM, Segretin ME, Morgenfeld MM, Wirth SA, Dus Santos MJ, Mozgovoj MV, Wigdorovitz A, Bravo-Almonacid FF (2010) High expression level of a foot and mouth disease virus epitope in tobacco transplastomic plants. Planta 231(2):387-395. https://doi.org/10.1007/ s00425-009-1058-4

Li Z, Yi Y, Yin X, Zhang Z, Liu J (2008) Expression of foot-andmouth disease virus capsid proteins in silkworm-baculovirus expression system and its utilization as a subunit vaccine. PloS one 3(5):e2273. https://doi.org/10.1371/ journal.pone. 0002273

Mierau I, Kleerebezem M (2005) 10 years of the nisin-controlled gene expression system (NICE) in Lactococcus lactis. Appl Microbiol Biotechnol 68(6):705-717. https:// doi.org/10.1007/s00253-005-0107-6

Ogra PL, Faden H, Welliver RC (2001) Vaccination strategies for mucosal immune responses. Clin Microbiol Rev 14(2):430-445. https://doi.org/10.1128/CMR.14.2.430445.2001

Pan L, Zhang Z, Lv J, Zhou P, Hu W, Fang Y, Chen H, Liu X, Shao J, Zhao F, Ding Y, Lin T, Chang H, Zhang J, Zhang Y, Wang Y (2014) Induction of mucosal immune responses and protection of cattle against direct-contact challenge by intranasal delivery with foot-and-mouth disease virus antigen mediated by nanoparticles. Int $\mathrm{J}$ Nanomed 9:5603-5618. https://doi.org/10.2147/IJN.S72318

Parida S, Anderson J, Cox SJ, Barnett PV, Paton DJ (2006) Secretory IgA as an indicator of oro-pharyngeal foot-andmouth disease virus replication and as a tool for post vaccination surveillance. Vaccine 24(8):1107-1116. https:// doi.org/10.1016/j.vaccine.2005.09.006

Segundo FD, Weiss M, Perez-Martin E, Dias CC, Grubman MJ, Santos Tde L (2012) Inoculation of swine with foot-andmouth disease SAP-mutant virus induces early protection against disease. J Virol 86(3):1316-1327. https://doi.org/ 10.1128/JVI.05941-11
Shi XJ, Wang B, Zhang C, Wang M (2006) Expressions of Bovine IFN-gamma and foot-and-mouth disease VP1 antigen in $P$. pastoris and their effects on mouse immune response to FMD antigens. Vaccine 24(1):82-89. https:// doi.org/10.1016/j.vaccine.2005.07.051

Wang G, Pan L, Zhang Y, Wang Y, Zhang Z, Lu J, Zhou P, Fang $Y$, Jiang S (2011) Intranasal delivery of cationic PLGA nano/microparticles-loaded FMDV DNA vaccine encoding IL-6 elicited protective immunity against FMDV challenge. PloS one 6(11):e27605. https://doi.org/10.1371/ journal.pone.0027605

Wang M, Pan L, Zhou P, Lv J, Zhang Z, Wang Y, Zhang Y (2015) Protection against foot-and-mouth disease virus in Guinea pigs via oral administration of recombinant Lactobacillus plantarum expressing VP1. PloS one 10(12):e0143750. https://doi.org/10.1371/journal.pone. 0143750

Xue M, Wang H, Li W, Zhou G, Tu Y, Yu L (2012) Effects of amino acid substitutions in the VP2 B-C loop on antigenicity and pathogenicity of serotype Asia1 foot-andmouth disease virus. Virol J 9:191. https://doi.org/10.1186/ 1743-422X-9-191

Yigang XU, Yijing LI (2008) Construction of recombinant Lactobacillus casei efficiently surface displayed and secreted porcine parvovirus VP2 protein and comparison of the immune responses induced by oral immunization. Immunology 124(1):68-75. https://doi.org/10.1111/j. 1365-2567.2007.02738.x

Yin C, Chen W, Hu Q, Wen Z, Wang X, Ge J, Yin Q, Zhi H, Xia C, Bu Z (2014) Induction of protective immune response against both PPRV and FMDV by a novel recombinant PPRV expressing FMDV VP1. Veterinary research 45:62. https://doi.org/10.1186/1297-9716-45-62

Publisher's Note Springer Nature remains neutral with regard to jurisdictional claims in published maps and institutional affiliations. 